\title{
Serum magnesium levels in preterm labour
}

\author{
Shakura Bhat ${ }^{1}$, Arfat Waheed ${ }^{2}$ \\ Sri Lanka Journal of Obstetrics and Gynaecology 2012; 34: 37-44
}

\begin{abstract}
Introduction: Preterm infants are at a greater risk of short term and long term complications including disabilities and impediments in growth and mental development. Hence, to predict and prevent the occurrence of preterm labour and delivery would go a long way to reduce the morbidity and mortality resulting from it. Preterm labour followed by preterm delivery is a major issue in India. Besides various etiologies, preterm labour may be due to a biochemical alteration, such as magnesium. Many recent findings have augmented the significance of magnesium in human health and disease. There is a mounting evidence that alterations in magnesium metabolism have a negative impact on pregnancy outcome. The aim of our investigation was to study the serum magnesium levels in preterm labour and to compare these values with those patients who had a term delivery, to find associated signs and symptoms and to suggest nutritional correction of prognostic value.
\end{abstract}

Methods: A case-control study was carried out to evaluate serum magnesium levels and associated symptoms in women with preterm labour (28-36 weeks) and compare them with patients in same gestational age who delivered at term (37-40 weeks).

Results: Patients in preterm labour have a significantly depressed serum magnesium level [mean, $1.343 \pm 0.09 \mathrm{meq} /$ lvs $1.875 \pm 0.013$ meq/1] $(\mathrm{p}<0.001)$ as compared to normal pregnancy. Preterm labour cases differed from controls in terms of significantly higher incidence of muscle cramps and change in the quality or quantity of vaginal discharge $(p<0.001)$. In our study, fall in the value of

\footnotetext{
${ }^{1}$ Senior Resident, Department of Obstetrics and Gynaecology, Govt. Medical College, Srinagar, India.

2 Senior Resident, Department of Anaesthesiology, SKIMS, Srinagar, India.

Correspondence: Shakura Bhat

E-mail: shakuraol@gmail.com
}

serum magnesium levels was of a significant magnitude in preterm labour as compared to normal controls $(p<0.001)$. Percentage of patients with preterm labour belonging to low socio-economic class was significantly higher than the upper and middle socio-economic classes $(\mathrm{p}<0.05)$.

Conclusion: Estimation of serum magnesium levels may be a useful parameter in pregnancy. Magnesium supplementation should be considered in pregnancy especially in high risk groups.

\section{Introduction}

Preterm labour is defined as the onset of labour prior to the completion of 37 weeks of gestation, in a pregnancy beyond 20 weeks of gestation ${ }^{1}$. WHO defines preterm labour as one where the labour starts before the 37 th completed week (<259 days) of gestation, counting from the first day of the last menstrual period ${ }^{2,3}$.

Spontaneous preterm labour is the leading cause of preterm delivery ${ }^{2,3}$. Although all births before 37 weeks of gestation are considered premature, births before 32 weeks of gestation ( $2 \%$ of all births) account for most neonatal deaths and disorders ${ }^{4}$. Incidence of preterm labour in India is $5-10 \%$ leading to $70-80 \%$ of perinatal deaths ${ }^{5}$. Late preterm births (between 34 weeks and 0 days and 36 weeks and 6 days) account for about $74 \%$ of all preterm births while the severe preterm birth (<32 weeks) rate has remained relatively constant during the last two decades ${ }^{6}$.

Besides varied etiology, preterm labour may be due to an alteration in basic biochemical functions of the body at cellular level stating emphasis to trace elements, of which magnesium, being one of them is a subject of interest nowadays. Magnesium is the second most positively charged ion found within the cells of body signifying its importance in the multitudes of physiological cellular function ${ }^{7}$. Serum levels of magnesium range from 1.5 to $2.1 \mathrm{meq} / \mathrm{1}^{7}$.

It is known that serum magnesium levels fall during pregnancy with gestational age. This decrease of magnesium plays an important role in the physiology of parturition. Decrease of magnesium in 
plasma may be responsible for decrease of same in myometrium leading to initiation of uterine contractions and labour ${ }^{5}$.

\section{Role of magnesium in causing preterm labour}

Since magnesium has an inhibitory role on myometrial contractions, attention has been paid to the role of magnesium deficiency in causing preterm labour. The inhibitory effect of magnesium on preterm labour contractions is attributed to antagonism of calcium mediated uterine contractions $^{8}$.

The regulatory pathway leading to uterine contraction begins with an increase in the intracellular free calcium concentration, which activates myosin light chain kinase (Mizuki and Associates, 1993). High concentrations of extracellular magnesium have been reported not only to inhibit calcium entry into myometrial cells but also to lead to high intracellular magnesium levels. This later effect has been reported to inhibit calcium entry into the cells presumably by blocking calcium channels (Mizuki and Associates, 1993) ${ }^{9}$.

Hence, hypomagnesemia leads to neuromuscular hyperexcitability resulting in muscle cramps and uterine hyperactivity. The hyperexcitability of uterine musculature induced by hypomagnesemia leads to increased cervical dilatation which in turn facilitates approach of vaginal micro-organisms into cervical canal and changes quality and quantity of vaginal discharge while uterine passage is being colonized by pathogenic micro-organisms ${ }^{10}$. The aim of this study is to determine the relationship between serum magnesium bevel and preterm delivery, so that the high morbidity and mortality related to prematurity could be reduced by early diagnosis of this deficiency and its correction.

\section{Methods}

The study was conducted in L. D. Maternity Hospital in Kashmir, India which is a tertiary care centre. The study was cleared by the hospital Ethics Committee. This prospective case-control study was conducted on a total of 200 primi gravida patients, divided into two groups of 100 each, as under:

Group 1 (cases): consisted of 100 patients with preterm onset of labour (between 28 and 37 weeks of gestation) and had preterm deliveries.

Group II (controls): consisted of 100 uncomplicated patients of comparable gestational age (28-37 weeks) attending the OPD for routine antenatal visits. These patients were then followed up till delivery.
Patients with any known high risk factor for preterm labour were excluded from the study as follows:

1. Previous history of recurrent abortions or preterm delivery.

2. Patients with recurrent urinary tract infections.

3. Patients with pre-eclampsia, polyhydramnios, antepartum haemorrhage, fetal congenital malformations, intrauterine death.

4. Patients with premature rupture of membranes.

5. Patients with any significant medical or surgical illness.

6. Patients with cervical incompetence or any uterine malformations.

7. Multigravida patients were not included in the study.

The study protocol went as follows:

- Detailed and comprehensive history taking as per proforma with emphasis on:

o Presence of muscle cramps during pregnancy (symptoms of hypomagnesemia).

o Change in the quality or quantity of vaginal discharge during preceding seven days.

o History regarding the socio-economic status.

- Physical examination (general, local and systemic) with meticulous per speculum and per vaginum examination to assess the integrity of cervix.

- Routine investigations.

\section{Method of collection of samples for the estimation of serum magnesium levels}

Blood samples taken from patients in Group I (cases) were collected at the time of admission to the labour ward, while as blood samples from the patients in Group II (controls) were collected in the outpatient department. They were followed up till delivery.

Samples hence collected were carried either in the same disposable syringe (which was used to draw the sample) or a gel separator vial or a vacutainer, to the Biochemistry Department of Government Medical College, Srinagar.

The quantitative assessment of serum magnesium levels was done photometrically at 530 nm on a HITACHI-912 auto analayser calibrated for magnesium, using a magnesium reagent kit marketed in India by diagnostic system (Diasys) Internationals.

The components of the reagent are:

1. Ethanolamine $(\mathrm{pH}=11): 750 \mathrm{mmol} / 1$ 
2. GEDTA (glycoethylenediamine): $60 \mu \mathrm{mol} / 1$

3. Blue of xylidyle: $110 \mu \mathrm{mol} / 1$

4. Detergents

\section{Statistical analysis}

Data were expressed as mean $\pm S D$ (standard deviation). For statistical analysis students ' $t$ ' test, chi-square test, and Post-Hoc test were used. 'P' value of $<0.05$ was considered as significant as $<0.001$ was considered as highly significant.

\section{Results}

The demographic characteristics were similar in both groups (Table 1).

There was a statistically highly significant difference between the two groups when compared for history of muscle cramps in pregnancy ( $p$ value $<0.001$ ). 89 out of 100 patients in Group I revealed the history of muscle cramps whereas only 51 out of 100 patients in Group II gave this history. Out of 100 patients in Group I, 83 complained of a change in the quality or quantity of vaginal discharge during preceding seven days, whereas only 16 out of 100 patients in Group II had a change in the quality or quantity of vaginal discharge during the same period. The two groups were compared statistically on the basis of this complaint and the difference was highly significant statistically $(p<0.001)$, chi square value of 89.78 .

Serum magnesium levels were compared for various socio-economic classes using one way ANOVA with post-HOC test, to make multiple comparisons. The comparison for serum magnesium levels between high $(1.813 \pm 0.109 \mathrm{SD})$ and middle $(1.700 \pm 0.165 S D)$ socio-economic classes revealed statistically significant difference $(p<0.05)$. The difference in serum magnesium levels between high socio-economic class $(1.813 \pm 1.109 \mathrm{SD})$ and low socioeconomic class (1.362 $\pm 0.118 \mathrm{SD})$ was found to be statistically highly significant $(\mathrm{p}<0.001)$. Similarly, the difference in serum magnesium levels between middle (1.3662 $\pm 0.118 \mathrm{SD})$ and low socioeconomic class $(1.362 \pm 0.118 \mathrm{SD})$ was statistically highly significant $(p<0.001)$. Finally the mean serum magnesium level in Group I (case group) was found to be $1.343 \mathrm{mg} / \mathrm{dl}$ with a S.D. of 0.09 whereas in Group II (control group) it was $1.875 \mathrm{mg} / \mathrm{dl}$ with a SD of 0.013 . The difference between the two groups was found to be statistically highly significant $(p<0.001)$.

Table 1. Age distribution

\begin{tabular}{|c|c|c|c|c|}
\hline \multirow[t]{2}{*}{ Age (years) } & \multicolumn{2}{|c|}{ Group I (cases) } & \multicolumn{2}{|c|}{ Group II (controls) } \\
\hline & No. & Percent & No. & Percent \\
\hline $24-26$ & 17 & 17 & 12 & 12 \\
\hline $27-29$ & 35 & 35 & 41 & 41 \\
\hline $30-32$ & 43 & 43 & 40 & 40 \\
\hline $33-35$ & 3 & 3 & 4 & 4 \\
\hline$>36$ & 2 & 2 & 3 & 3 \\
\hline Total & 100 & 100 & 100 & 100 \\
\hline Mean & \multicolumn{2}{|c|}{$28.63 \pm 2.80$} & $28.90 \pm 2.10$ & $\mathrm{P}=0.44(\mathrm{NS})$ \\
\hline
\end{tabular}

NS = Non-significant

The age of the patient varied from 24-37 years. Mean age in Group 1 is 28.63 as compared to mean age of 28.90 in Group 2. There was no statistically significant difference between the two groups $(\mathrm{P}=0.44)$. 


\section{Discussion}

Over the past two decades a marked increase in the survival of very low birth weight infants has been seen. However, a reduction in mortality has not been accompanied by a reduction in neonatal morbidity or long term handicaps ${ }^{11}$. Premature infants are at a greater risk of short term and long term complications including disabilities and impediments in growth and mental development ${ }^{12}$. Hence, to predict and prevent the occurrence of preterm labour and delivery would go a long way to reduce the morbidity and mortality resulting from it.

Table 2. Distribution by socio-economic class

\begin{tabular}{lrcccc}
\hline $\begin{array}{l}\text { Socio-economic } \\
\text { class }\end{array}$ & \multicolumn{2}{c}{$\begin{array}{c}\text { Group I } \\
\text { (cases) }\end{array}$} & & & $\begin{array}{c}\text { Group II } \\
\text { (controls) }\end{array}$ \\
\cline { 2 - 3 } \cline { 5 - 6 } & No. & Percent & & No. & Percent \\
High & 6 & 6 & & 16 & 16 \\
Middle & 36 & 36 & & 39 & 39 \\
Low & 58 & 58 & & 45 & 45 \\
Total & 100 & 100 & & 100 & 100 \\
Statistical analysis $\mathrm{P}<0.05$ (significant)
\end{tabular}

Majority, 58 patients in Group I belonged to low socio-economic class, whereas in Group II only 45 patients belonged to this class. 6 and 16 patients in Group I and II respectively belonged to high socioeconomic class. 36 and 39 patients in group I and II respectively were from middle socio-economic class. 'P' value $<0.05$.

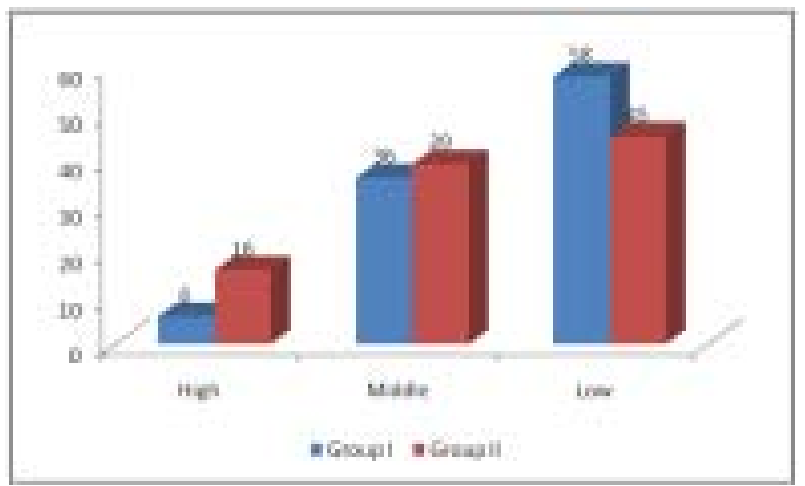

Figure 1. Comparison for distribution of patients by socio-economic classes between Group I and Group II.

The aim of our investigation was to study the serum magnesium levels in preterm labour and to compare these values with those patients who had a term delivery, to find associated signs and symptoms and to suggest nutritional correction of prognostic value.

Many recent findings have augmented the significance of magnesium in human health and disease $^{13}$. There is a mounting evidence that alterations in magnesium metabolism have a negative impact on pregnancy outcome ${ }^{13}$. Exact cause of hypomagnesemia in patients of preterm labour is not known but nutritional and socio-economic factors have been blamed for it. Neuromuscular hyperexcitability is an initial problem cited in individuals who have or are developing magnesium deficiency. Neuromuscular hyperexcitability in turn leads to uterine hyperactivity resulting in premature onset of labour ${ }^{14}$. The role of hypomagnesemia in preterm labour contractions is attributed to loss of antagonism of calcium mediated uterine contractions ${ }^{8}$.

Table 3a. History of muscle cramps

\begin{tabular}{lccccc}
\hline $\begin{array}{l}\text { History of } \\
\text { muscle cramps }\end{array}$ & \multicolumn{2}{c}{$\begin{array}{c}\text { Group I } \\
\text { (cases) }\end{array}$} & & \multicolumn{2}{c}{$\begin{array}{c}\text { Group II } \\
\text { (controls) }\end{array}$} \\
\cline { 2 - 3 } \cline { 5 - 6 } & No. & Percent & & No. & Percent \\
\hline Present & 89 & 89 & & 51 & 51 \\
Absent & 11 & 11 & & 49 & 49 \\
Total & 100 & 100 & & 100 & 100 \\
$\begin{array}{l}\text { Statistical analysis } \\
\text { significant) }\end{array}$ & $\chi^{2}=34.38 ;$ & P<0.001 & (highly \\
\hline
\end{tabular}

89 patients in Group I gave a history of muscle cramps during pregnancy, whereas only 51 patients from Group II had this complaint. The difference between the two groups was found to be highly significant 2 (chi-square) $=34.38 ; \mathrm{p}<0.001)$.

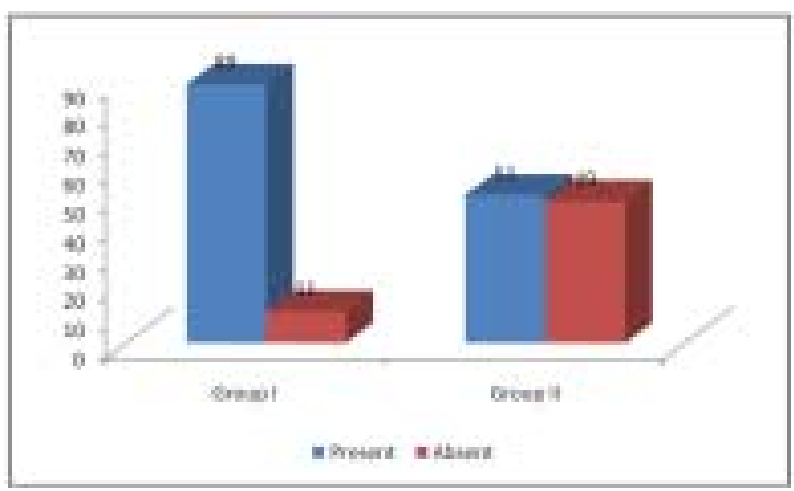

Figure 2. Comparison for history of muscle cramps between Group I and Group II. 
Table $3 \mathbf{b}$. History of changes in quality or quantity of vaginal discharge in preceding seven days

\begin{tabular}{|c|c|c|c|c|}
\hline \multirow{2}{*}{$\begin{array}{l}\text { Changes in the } \\
\text { status of vaginal } \\
\text { discharge }\end{array}$} & \multicolumn{2}{|c|}{$\begin{array}{c}\text { Group I } \\
\text { (cases) }\end{array}$} & \multicolumn{2}{|c|}{$\begin{array}{l}\text { Group II } \\
\text { (controls) }\end{array}$} \\
\hline & No. & Percent & No. & Percent \\
\hline Present & 83 & 83 & 16 & 16 \\
\hline Absent & 17 & 17 & 84 & 84 \\
\hline Total & 100 & 100 & 100 & 100 \\
\hline
\end{tabular}

History of change in the quality or quantity of vaginal discharge in the preceding seven days was given by 83 patients in Group I while as only 16 patients in Group II revealed this history. The difference between the two groups was found to be statistically highly significant $(\mathrm{p}<0.001)$. Chisquare $=89.78$.

In our study most of the patients presenting with preterm labour i.e. in Group I belonged to low socio-economic class (58 out of 100 cases), whereas 6 out of 100 and 36 out of 100 patients in Group I belonged to high and middle socio-economic classes respectively (Table 2 and 4). In Group II (controls), most of the patients, 45 out of 100 belonged to low socio-economic class, whereas 39 and 16 patients belonged to middle and high socio-economic classes respectively. The percentage of preterm labour cases belonging to low socio-economic class was significantly higher than the upper and middle socio-economic classes $(\mathrm{p}<0.05)$. Previous clinical studies have also shown that the preterm birth rate was highest in low socio-economic class ${ }^{5,15,16}$. A significantly higher incidence of muscle cramps and change in the quality or quantity of vaginal discharge (Table $3 a$ and $3 b$ ) as compared to normal pregnancy women delivering at term was seen in our study comparable to the observations of ${ }^{10,17}$. The mechanism of preterm labour could be explained by hyperexcitability of uterine musculature induced by hypomagnesemia leading to increased cervical dilatation which in turn facilitates the approach of vaginal micro-organisms into the cervical canal and changes the quality and quantity of vaginal discharge.

Table 4. Comparative study of serum magnesium levels in pregnant women between different socio-economic classes

\begin{tabular}{lcccccc}
\hline Socio-economic class & \multirow{2}{*}{ No. of cases } & \multicolumn{3}{c}{ Serum magnesium levels } & \multirow{2}{*}{ P-value } & Remarks \\
\cline { 3 - 5 } & & Range $(m g / d l)$ & Mean (mg/dl) & SD (mg/dl) & & \\
\hline High vs. & 22 & $1.63-2.07$ & 1.8133 & 0.109 & $<0.05$ & $\mathrm{~S}$ \\
Middle & 75 & $1.35-1.95$ & 1.7000 & 0.165 & - & - \\
Middle vs. & 75 & $1.35-1.95$ & 1.7000 & 0.165 & $<0.001$ & $\mathrm{HS}$ \\
Low & 103 & $1.23-1.85$ & 1.3662 & 0.118 & - & - \\
High vs. & 22 & $1.63-2.07$ & 1.8133 & 0.109 & $<0.001$ & $\mathrm{HS}$ \\
Low & 103 & $1.23-1.85$ & 1.3662 & 0.118 & & \\
\hline
\end{tabular}

$\mathrm{S}=$ significant; HS = highly significant

Serum magnesium levels were compared among high, middle and low socio-economic groups. High socioeconomic group had a mean serum magnesium of $1.913 \pm 0.109$, middle socio-economic group had serum magnesium of $1.7000 \pm 0.16$ and low socio-economic group had serum magnesium levels of $1.3662 \pm 0.118$. Comparison between the three groups showed that the difference in serum magnesium level was highly significant $(p<0.001)$. 


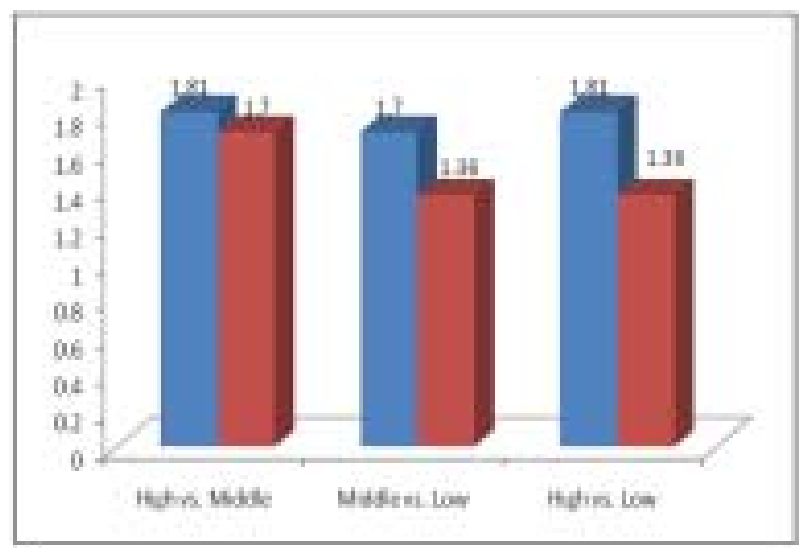

Figure 3. Comparative study of serum magnesium levels in pregnant women between different socioeconomic classes.

In our study, fall in the value of serum magnesium levels was of a greater magnitude in Group I as compared to Group II (Table 5). The mean serum magnesium level at 28-30 weeks of gestation was $1.37 \pm 0.055 \mathrm{mg} / \mathrm{dl}$ in Group I as compared to a value of $1.97 \pm 0.073 \mathrm{mg} / \mathrm{dl}$ in Group II. The difference was found to be statistically highly significant $(p<0.001)$.
At 31-33 weeks of gestation, mean serum magnesium level in Group I was $1.35 \pm 0.063 \mathrm{mg} / \mathrm{dl}$ as compared to $1.89 \pm 0.084 \mathrm{mg} / \mathrm{dl}$ in Group II. The statistical difference between the two groups was highly significant $(p<0.001)$. The serum magnesium level in Group I at the gestational ages of 34-36 weeks was $1.31 \pm 0.060 \mathrm{mg} / \mathrm{dl}$ while as in Group II the mean was $1.77 \pm 0.111(p<0.001$, highly significant statistical difference).

Previous work has also found that the serum magnesium level is slightly depressed or unchanged during first and second trimester of pregnancy, but significantly decreases during third trimester especially in last two months of pregnancy ${ }^{18,19}$. Lastly serum magnesium levels between Group I and Group II were compared (Table 6). In Group I, serum magnesium levels ranged from 1.21 to $1.64 \mathrm{mg} / \mathrm{dl}$ with a mean of $1.343 \mathrm{mg} / \mathrm{dl}$ with a SD of 0.09 . In Group II, serum magnesium levels ranged from 1.61 to 2.07 $\mathrm{mg} / \mathrm{dl}$ with a mean of $1.875 \mathrm{mg} / \mathrm{dl}$ with a SD of 0.129 . Hence, serum magnesium levels are lower in Group I as compared to Group II. The comparison between the two groups by using students ' $t$ ' test revealed that there is a statistically highly significant difference between the two groups $(p<0.001)$.

Table 5. Serum magnesium levels at different gestational ages (graph)

\begin{tabular}{lccccc}
\hline \multirow{2}{*}{$\begin{array}{c}\text { Gestational age } \\
\text { (weeks) }\end{array}$} & \multicolumn{2}{c}{ Serum magnesium levels $(\mathrm{mg} / \mathrm{dl})$} & & \multicolumn{2}{c}{ Statistical analysis } \\
\cline { 2 - 3 } & Group I & Group II & & p-value & Remarks \\
\hline $28-30$ & $1.37 \pm 0.055$ & $1.97 \pm 0.073$ & & $<0.001$ & HS \\
$31-33$ & $1.35 \pm 0.063$ & $1.89 \pm 0.84$ & & $<0.001$ & HS \\
$34-36$ & $1.31 \pm 0.060$ & $1.77 \pm 0.111$ & & $<0.001$ & HS \\
\hline
\end{tabular}

HS = Highly significant

Serum magnesium levels taken at different gestational ages were studied and it was found that the levels decreased with increasing gestational age for both Group I as well as Group II.

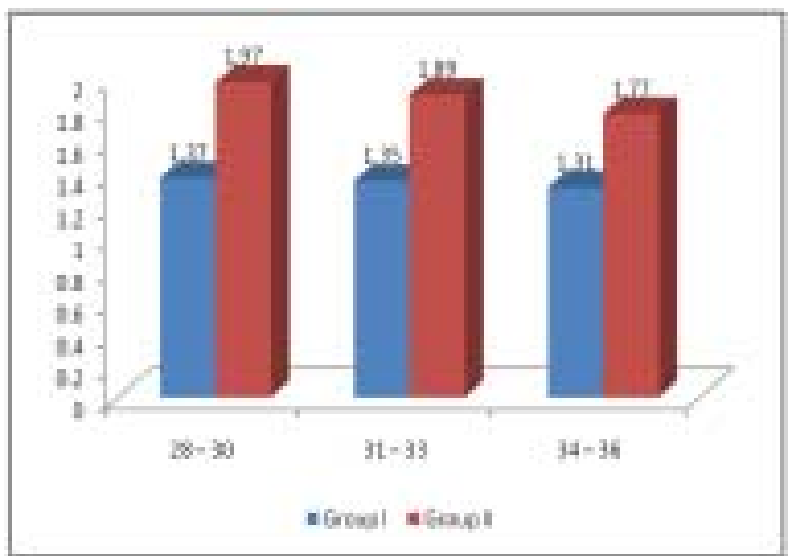

Figure 4. Comparison of serum magnesium levels at different gestational ages between Group I and Group II. 
Table 6. Comparison of serum magnesium levels between Group I and Group II

\begin{tabular}{|c|c|c|c|c|c|c|c|}
\hline \multirow[t]{2}{*}{ Group } & \multirow[t]{2}{*}{ No. of patients } & \multicolumn{3}{|c|}{ Serum magnesium levels $(\mathrm{mg} / \mathrm{dl})$} & \multicolumn{3}{|c|}{ Statistical analysis } \\
\hline & & Range & Mean & $S D$ & $' t^{\prime}$ & p-value & Remarks \\
\hline Group I (cases) & 100 & $1.21-1.64$ & 1.343 & 0.09 & 36.597 & $<0.001$ & HS \\
\hline Group II (controls) & 100 & $1.61-2.07$ & 1.875 & 0.013 & & & \\
\hline
\end{tabular}

HS = highly significant

The mean serum magnesium level in Group I (case group) was found to be $1.343 \mathrm{mg} / \mathrm{dl}$ with a SD of 0.09 . The mean serum magnesium level in Group II (control group) was $1.875 \mathrm{mg} / \mathrm{dl}$ with a SD of 0.013 . The difference between the two groups was found to be statistically highly significant $(p<0.001)$.

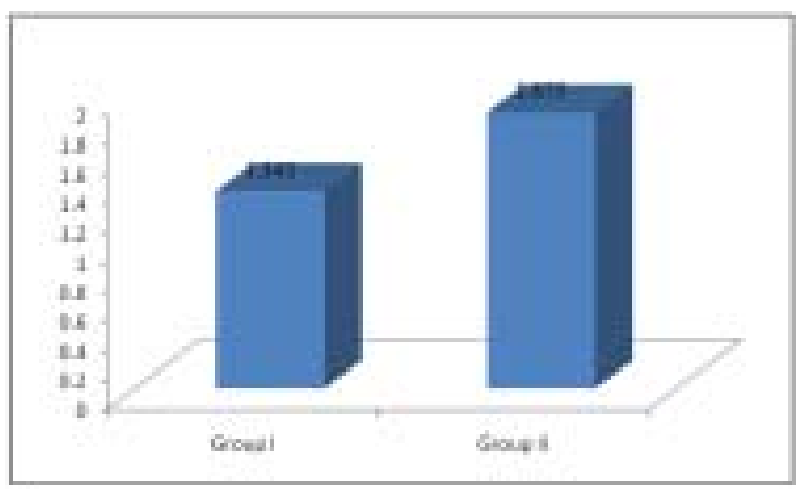

Figure 5. Comparison of serum magnesium levels between Group I and Group II.

Recent work has pointed towards hypomagnesemia a significant risk factor for preterm labour and that serum magnesium estimation must be done in cases of pregnancy to predict and prevent preterm labour ${ }^{5,10,19}$. Prophylactic magnesium supplementation in such cases is an issue of debate with some studies in favour ${ }^{20,21,22,23}$ whereas some studies showing no effect in preventing preterm labour ${ }^{24,25}$. However, further research agenda at the community level should be directed to see the therapeutic use of magnesium supplementation for prevention of preterm labour.

\section{Conclusions}

Serum magnesium levels can be used as a predicting tool of preterm labour and serum magnesium estimation must be done in cases of pregnancy to prevent preterm labour. Magnesium supplementation may be considered in patients with decreased serum magnesium levels to prevent preterm labour.

\section{References}

1. American College of Obstetricians and Gynecologists.
Preterm Labour. Technical Bulletin No. 206, Washington DC: ACOG, 1995. Int J Gynecol Obstet 1995; 50(3): 303313.

2. Anotayanonth S, Subhedar NV, Neilson JP, Harigopal S. Betamimetics for inhibiting preterm labour. Cochrane Database of Systematic Review 2004, Issue 4, CD 004352.

3. Vijay R, Prasad GS. Tocolysis with ritodrine: a comparative study in preterm labour. Pak J Med Sci 2006; 22: 64-69.

4. Goldenberg RL, Rouse DJ. Prevention of premature birth. New England Journal of Medicine 1998; 5: 313-20.

5. Kamal S, Sharan A, Kumar U, Shahi SK. Serum magnesium level in preterm labour. Indian J Pathol Microbiol 2003; 46(2): 271-3.

6. Arias, Deftary, Bhide. Preterm parturition syndrome. Practical Guide to High Risk Pregnancy and Delivery: A South Asian Perspective, 3rd Edition 2008: 193-204.

7. Whitney EN, Cataldo CB, Rolfes SR. 6th Edition. Understanding Normal and Clinical Nutrition, Belmont, CA: Wadsworth, 1996.

8. Swain R, Kaplan, Machlis B. Magnesium for the next millennium. South Med J 1999; 92: 1040-7.

9. Whitney EN, Cataldo CB, Rolfes SR. 4th Edition. Understanding Normal and Clinical Nutrition. Belmont CA: Wadsworth, 1996. 
10. Hantoushzadeh S, Jafarabadi M, Khazardoust S. Serum magnesium levels, muscle cramps and preterm labour. Int J Gynae Obst 2007; 98(2): 153-4.

11. Guinn D, Gibbs R. Infection related preterm birth - a review of evidence. Neo Reviews 2002; 3: e86.

12. Goldenberg RL, Culhane JF, Iams JD, Romero R. Epidemiology and causes of preterm birth. Lancet 2008; 371: $75-84$.

13. NIH Consensus. Development panel on the effect of corticosteroids for fetal maturation on perinatal outcomes. Effect of corticosteroids for fetal maturation on perinatal outcomes. JAMA 1995; 273: 413-8.

14. Durlach J, Bac P, Durlach V, Bara M, Guiet-Bara A. Neurotic, neuromuscular and autonomic nervous form of magnesium imbalance. Magnesium Res 1997; 10: 169-95.

15. Peacock JL, Bland JM, Anderson HR. Preterm delivery: effects of socio-economic factors, psychological stress, smoking, alcohol and caffeine. BMJ (Clinical Research Ed.) 1995; 311: 531-5.

16. Sharma A, Kharb S, Vineeta, Gulati N. Serum magnesium levels in preterm labour in relation to socioeconomic status. Indian Journal of Biochemistry 1998; 13: 123-5.

17. Bartl W, Riss P. Pathophysiology and therapy of magnesium deficiency in pregnancy. Z Gegurtshilfe Perinatol 1982; 186(6): 335-7.
18. Potnis AV, Patel PV, Purandare BN. Magnesium - the ignored element during pregnancy. J of Obst and Gynae of India 1977; 27: 343-5.

19. Kurzel RB. Serum magnesium levels in pregnancy and preterm labour. Am J Perinatol 1991; 8(2): 119-27.

20. Vilma K, Balazs M, Morvay F, Varrenka Z, Szekely A, Szucs M. Effect of magnesium supply on spontaneous abortion and premature birth and on intrauterine fetal development, experimental epidemiological study. Magnesium Bulletin 1981; 3(1): 73-79.

21. Valenzuela GJ, Munson LA. Magnesium and pregnancy. Magnesium 1987; 6(3): 128-35.

22. Kovac L, Molnar BG, Huhn E, Bodis L. Magnesium substitution in pregnancy - randomized double blind study. Geburtshilfe Frauenheilkd 1988; 48(8): 595-600.

23. Spatling L, Spatling G. Magnesium supplementation in pregnancy. A double blind study. Br J Obstet Gynecol 1988; 95(2): 120-5.

24. Skajaa K, Darup I, Sandstrom BM. Magnesium intake and status and pregnancy outcome in Danish population. $\mathrm{Br} \mathrm{J}$ Obstet Gynecol 1991; 98: 919-28.

25. Martin RW, Perry KJ, Hess LW, Martin JJ, Morrison JC. Oral magnesium and prevention of preterm labour in a high risk group of patients. Am J Obstet Gynecol 1992; 166: 144-7. 